\title{
A VEP study in sleeping and awake one-month-old infants and its relation with social behavior
}

\author{
Sara Cruz ${ }^{\mathrm{a}, *}$, Alberto Crego ${ }^{\mathrm{a}}$, Eugénia Ribeiro ${ }^{\mathrm{b}}$, Óscar Gonçalves ${ }^{\mathrm{a}, c, \mathrm{~d}}$, Adriana Sampaio ${ }^{\mathrm{a}}$ \\ a Neuropsychophysiology Laboratory, CIPsi School of Psychology, University of Minho, Braga, Portugal \\ b CIPsi School of Psychology, University of Minho, Braga, Portugal \\ ${ }^{\mathrm{c}}$ Department of Counseling and Applied Educational Psychology, Bouvé College of Health Sciences, Northeastern University, Boston, MA, USA \\ d Spaulding Center of Neuromodulation, Department of Physical Medicine E Rehabilitation, Spaulding Rehabilitation Hospital and Massachusetts General \\ Hospital, Harvard Medical School, Boston, MA, USA
}

\section{A R T I C L E I N F O}

\section{Article history:}

Received 24 October 2014

Received in revised form

11 December 2014

Accepted 11 December 2014

Available online 15 December 2014

\section{Keywords:}

Infancy

State

VEPs

Neurobehavioral assessment

NBAS

Development

\begin{abstract}
A B S T R A C T
With the present study we aimed to analyze the relationship between infants' behavior and their visual evoked-potential (VEPs) response. Specifically, we want to verify differences regarding the VEP response in sleeping and awake infants and if an association between VEP components, in both groups, with neurobehavioral outcome could be identified. To do so, thirty-two full-term and healthy infants, approximately 1-month of age, were assessed through a VEP unpatterned flashlight stimuli paradigm, offered in two different intensities, and were assessed using a neurobehavioral scale. However, only 18 infants have both assessments, and therefore, these is the total included in both analysis. Infants displayed a mature neurobehavioral outcome, expected for their age. We observed that P2 and N3 components were present in both sleeping and awake infants. Differences between intensities were found regarding the P2 amplitude, but only in awake infants. Regression analysis showed that N3 amplitude predicted an adequate social interactive and internal regulatory behavior in infants who were awake during the stimuli presentation. Taking into account that social orientation and regulatory behaviors are fundamental keys for social-like behavior in 1-month-old infants, this study provides an important approach for assessing physiological biomarkers (VEPs) and its relation with social behavior, very early in postnatal development. Moreover, we evidence the importance of the infant's state when studying differences regarding visual threshold processing and its association with behavioral outcome.
\end{abstract}

(c) 2014 Elsevier Ltd. All rights reserved.

\section{Introduction}

From birth, infants respond differently to the surrounding environment by changing their state, being able to attend to distinct visual stimuli. This ability is especially noticeable in their preference for the human face, particularly their mother's, which is addressed by the infant's eye gaze and the imitation of face-like patterns (Johnson et al., 1991). Once this orientation behavior towards the environment is displayed very early, several authors have been interested in characterizing young infants according to their reactivity to external stimuli (Mikkola et al., 2007; Pihko et al., 2004; Ceponiene et al., 2002). This reactivity can

\footnotetext{
* Corresponding author at: Neuropsychophysiology Laboratory, School of Psychology, University of Minho, Campus de Gualtar, 4710-057, Braga, Portugal. Tel.: +351253604220.

E-mail address: saracruz@psi.uminho.pt (S. Cruz).
}

be decoded through different behavioral characteristics (Rothbart, 2007; Calkins et al., 1996). For instance, Feldman and Eidelman (2006) showed that full-term newborns exhibit mature neurobehavioral profiles emphasizing their state organization, motor maturity and higher orientation scores to both social and nonsocial stimuli, as well as more settled cognitive development and interactive behavior when assessed later.

Across the infancy period, developmental and behavioral changes are accompanied by brain alterations as the infant's response to the environmental stimuli changes in parallel to brain maturation mechanism (Huttenlocher, 2009). Different studies have used psychophysiological techniques, such as event-related potentials (ERP), to assess changes in the infant's brain activity that occur in response to a stimulus that is repeatedly presented. Particularly, the study of visual evoked potentials (VEPs) has been widely used to expand our knowledge about the different neurodevelopmental pathways in very young infants, allowing for further comprehension about the visual maturation and cortical function 
mechanisms, as well as visual sensory processing (McGlone et al., 2013).

Evidence from VEP studies has suggested that, at approximately 1 month of age, the presence of early VEP components, such as P2 or N3, play an important role as indicators of healthy brain development, as their presence is associated with visual processing and proper neural maturation of the visual cortex (McGlone et al., 2013; Kato and Watanabe, 2006; Benavente et al., 2005; Kraemer et al., 1999). Indeed, evidence from several studies has shown that the $\mathrm{P} 2$ and $\mathrm{N} 3$ are present in early ages, being characterized as the most robust components in sensory stimuli processing, translating a mature VEP neural development (McGlone et al., 2013). However, there seems to be little consensus regarding the VEP characteristics when assessed in awake or sleeping infants (Mercuri et al., 1995; Whyte et al., 1987). In fact, some studies have suggested differences regarding VEP components' latency and amplitude depending on the infant's alertness state, particularly reporting that awake infants display greater P2 amplitudes and shorter latencies (Benavente et al., 2005; Mercuri et al., 1995). In a study, conducted by Shepherd et al. (1999), with only a fullterm infant, the authors have found differences regarding the N1 and P2 amplitude and peak latencies depending on the infant's behavioral state. Indeed, infants' state and its implications for development have been addressed, indicating that both sleeping and awake states seem essential for development and neural maturation mechanisms (Mento and Bisiacchi, 2012; Fifer et al., 2010).

More commonly, alterations in VEP morphology are linked to a typical developmental features that are mirrored in neurobehavioral changes, with implications for both cognitive and social domains (Liu et al., 2010; Kato and Watanabe, 2006; Tsuneishi et al., 1995). These physiological differences, when correlated with neurodevelopmental outcomes, may be used as physiological markers for the early identification of developmental pathways (Liu et al., 2010; Isler et al., 2007; Majnemer et al., 1990). Associating visual processing through a VEP assessment in very young infants may be a useful approach to identify abnormal developmental characteristics (Stanley et al., 2009), thereby, contributing to a better understanding about its implications in cognitive and behavior abnormalities (Kirk et al., 2013; Sampaio et al., 2008).

Therefore, with the present study, our objective was to identify VEP components in 1-month-old infants' response to an unpatterned flashlight visual stimulus offered in two different intensities in awake and sleeping infants. Additionally, we aimed to analyze if the VEP response can predict adjusted neurobehavioral outcomes. Taking into account previous studies, our hypothesis was that the VEP components could be identified in very young infants in the two intensities, with greater activation being displayed in response to the higher intensity stimulus. Moreover, we hypothesized that this response differed according to the infants' state (sleeping vs. awake infants), with this physiological response predicting mature neurobehavioral profiles with respect to their reactivity to both external (orienting/interactive characteristics) and internal stimuli (regulation characteristics).

\section{Materials and methods}

\subsection{Participants}

This study was reviewed and accepted by the ethical committee from Hospital Pedro Hispano in Matosinhos, Portugal. Mother/infant dyads were recruited at the Obstetric Department when the infant was born. Thirty-two healthy, full-term infants, aged 1-month-old, were assessed regarding their VEP response (17 [53\%] sleeping and 15 [47\%] awake). From this total, we lost 14 participants' neurobehavioral assessment due to different distress
Table 1

Infant's health characteristics at the time of recruitment and collection.

\begin{tabular}{lll}
\hline & Participant's characteristics & \\
\hline At recruitment time & $\begin{array}{l}\text { Gestational age } \\
\text { (mean weeks) } \\
\text { Weight } \\
\text { (mean kg) }\end{array}$ & 39 \\
Height \\
(mean kg) & 3235 \\
Apgar score & 48.7 \\
(10th min) & 10 \\
At collection time & $\begin{array}{l}\text { Age } \\
\text { (mean days) } \\
\text { Total with VEPs } \\
\text { Total with NBAS } \\
\text { Total with VEPs and NBAS }\end{array}$ & 33 \\
& & 32 \\
\end{tabular}

presented at the moment of data collection (infant's behavioral distress, mothers' availability or even due to feeding routines). Therefore, overall, the total of infants having both the VEP and neurobehavioral assessments is 18 (10 girls and 8 boys; 9 in the sleep group and 9 in the awake group) - see Table 1 .

For the state characterization we used the states concept developed and described by Brazelton and Nugent (Brazelton and Nugent, 1995). We considered as being in sleeping state those infants who presented eyes close, regular respiration and no or little spontaneous body movements (either in deep or active sleep). The awake infants were characterized as having bright look, directed to the stimuli, minimal motor activity and reactive to the stimuli. In this category, we also included infants that were irritable during the stimuli presentation.

\subsection{VEP stimuli}

White flashes were presented using the lamp of a Grass PS33Plus Photic Stimulator (Astro-Med Inc., Warwick, USA), positioned at $50-\mathrm{cm}$ distance from the infant. The stimulus was offered in two blocks of repeated flashes with the same frequency $(2 \mathrm{~Hz})$ separately, and each block with a different intensity, during $1 \mathrm{~min}$. The stimulation intensity was set at $1(0.09 \mathrm{~J}$ - intensity 1$)$ and 2 (0.18 J - intensity 2) in the flash position (Odom et al., 2010). For each block presentation, the flash position was organized for the purpose of achieving different combinations and offered in a pseudo-randomized way ( 1 and $2 ; 2$ and 1 ) so that we could control the presentation order effect.

\subsection{VEP data recording and analysis}

Electroencephalographic activity was recorded with a QuickAmpTM system, with a 32-electrode ActicapTM System inserted in a cap with a frontopolar ground and average referenced. 32 recording electrodes were placed at Fp1, Fp2, F3, F4, Fz, F7, F8, FC1, FC2, FC5, FC6, T7, C3, Cz, C4, T8, TP9, CP1, CP2, CP5, CP6, TP10, P3, P4, Pz, $\mathrm{P7}, \mathrm{P} 8, \mathrm{PO}, \mathrm{O} 1, \mathrm{Oz}, \mathrm{O} 2, \mathrm{PO} 10$ in accordance with the international 10-20 system (Jasper, 1958) and electrode impedances were kept below $10 \mathrm{k} \Omega$ for all participants. EEG signals were continuously amplified, digitized at sample rate of $250 \mathrm{~Hz}$ and filtered on-line with a $0.01-100 \mathrm{~Hz}$ ( $12 \mathrm{~dB} /$ octave slope) band pass filter using a Quick-AmpTM system amplifier and Brain Vision Recorder software (Version 1.20). All EEG data was analyzed with Brain Vision Analyzer software (Version 2.0.1). The EEG was digitally filtered off-line with a $0.2-20 \mathrm{~Hz}$ band pass filter and $50 \mathrm{~Hz}$ notch filter. It was then corrected for ocular artifacts by the semiautomatic procedure in independent component analysis (ICA) (Jung et al., 2000) and segmented into epochs of $600 \mathrm{~ms}$ from $100 \mathrm{~ms}$ pre-stimulus to $500 \mathrm{~ms}$ post-stimulus. Next, baseline correction was applied and 
Table 2

Mean (SEs) values for N2, P2 and N3 peaks amplitude ( $\mu \mathrm{V}$ ) and latency (ms) recorded at 01, O2 and Oz.

\begin{tabular}{|c|c|c|c|c|}
\hline & \multicolumn{2}{|l|}{ P2 } & \multicolumn{2}{|l|}{ N3 } \\
\hline & Latency & Amplitude & Latency & Amplitude \\
\hline \multicolumn{5}{|l|}{ Awake infants } \\
\hline Low intensity & $204.36(8.86)$ & $5.69(1.43)$ & $340.84(15.68)$ & $-2.52(0.64)$ \\
\hline High intensity & 227.69 (15.89) & $8.61(1.86)$ & $377.24(15.32)$ & $-1.76(0.66)$ \\
\hline \multicolumn{5}{|l|}{ Sleeping infants } \\
\hline Low intensity & $199.71(11.20)$ & $6.24(1.33)$ & $320.31(15.04)$ & $-2.30(1.01)$ \\
\hline High intensity & $213.61(15.30)$ & $5.98(1.28)$ & 335.16 (18.99) & $-3.44(1.17)$ \\
\hline
\end{tabular}

epochs exceeding $\pm 200 \mu \mathrm{V}$ at any scalp electrode were rejected. Finally, individual subject averages ERPs time-locked to the two different stimuli (lower and higher intensity) were computed separately. A minimum of 30 trials per average was recorded and the procedure repeated to check reproducibility.

Grand mean averages were computed for each stimulus and used to determine the latency ranges in which the cortical VEP components were measured. The identification of peaks in individual averages were made with a semiautomatic peak detection procedure and, subsequently reviewed and manually corrected at $\mathrm{O} 1, \mathrm{Oz}$ and $\mathrm{O} 2$ electrodes for each participant. When peak identification was doubtful, responses from all electrodes were compared, and the response was compared to the grand mean averages.

The variability in the response was considerable, which is common among infants, but, according to the typical neonatal VEP waveform morphology reported by McGlone et al. (2013) it was generally characterized by a positive wave (P2) peaking around $200 \mathrm{~ms}$ followed by a broad negative wave (N3) peaking around $350 \mathrm{~ms}$ (see Table 2), clearly identified in all participants. Earlier peaks, N1, P1 and N2 were much less frequently evoked and were smaller in comparison with the later peaks; therefore, these components were not analyzed.

\subsection{Neurobehavioral assessment}

For the neurobehavioral assessment, we used the neonatal behavioral assessment scale (NBAS) (Als et al., 1977). A trained and reliable examiner on the NBAS carried out the assessment and the codification process. This scale assesses the newborns' infant behavioral repertoire through 28 behavioral items coded on a 9point scale and the neurological state through 18 reflex items coded on a 4-point scale. It is organized into 7 clusters (Lester et al., 1982): habituation, orientation, motor, range of state, regulation of state, autonomic stability and reflexes.

Taking into account the objectives of this study, we considered the following clusters to characterize the infants' external and internal behavior: (a) orientation, for external behavior assessment, and (b) regulation of state to assess their internal regulation ability (Sprangler et al., 1996; Lester et al., 1982; Als et al., 1977). Indeed, both clusters are assumed to mirror social characteristics in such young infants as social involvement imply alert and orienting abilities, as well as internal regulatory processes, in order to attend and respond to the surrounding stimuli (Brazelton and Nugent, 1995). And once the visual assessment is proposed as an indicator of cortical function (Atkinson, 2002; Brazelton and Nugent, 1995) when associated to infants' external and internal responses to stimuli, we assume it as a psychophysiological marker of social behavior.

For the orientation score, the mean of the items inanimate visual, inanimate auditory, inanimate visual-auditory, animate visual, animate auditory, animate visual-auditory and alertness was calculated; likewise, regarding the regulation of state, the score was obtained by calculating the mean of the items cuddliness, consolability, self-quieting and hand-to-mouth. In both clusters, higher punctuations reflect mature behavioral performances, as expected for this age.

\subsection{Procedure}

Data collection was carried out in a quiet room with a temperature approximately $20-25^{\circ} \mathrm{C}$ with luminosity and sound features controlled. Once the family arrived, the informed consent was obtained. We started either with the neurobehavioral assessment or with the psychophysiological recordings, considering the newborns' state. Regarding the physiological procedure, we began the data collection by cleaning the infant's scalp with distilled water, immediately followed by placing the electrode cap on the infant's head. Then, the infant was placed in his/her mother's lap, as she was seated in a comfortable chair, and the researcher held the stimulating lamp at a $50-\mathrm{cm}$ distance from the infant's face as flashes were directed towards his or her eyes. Mothers were asked to stay quiet during the sessions and not to move themselves or the infant. The use of the pacifier was the maneuver recommended for calming down the baby if needed. When necessary, the session was interrupted to calm down the infant and afterwards the stimuli delivering started fresh. Therefore, the infant's state was maintained in each visual stimuli intensity block. The sessions' data collection duration was approximately $30 \mathrm{~min}$.

\subsection{Data analyses}

\subsubsection{VEPS}

Data statistical analysis was performed using the IBM SPSS Statistics 22.

For each component (P2 and N3), separate repeated-measures analyses of variance ANOVAs were conducted with measurements of latency (ms) and amplitude $(\mu \mathrm{V})$ from an average of the three occipital electrodes $(\mathrm{O} 1, \mathrm{Oz}$ and $\mathrm{O} 2$ ), the intensity stimulus (low and high) as within-subject factor, and infant's state as betweensubjects factor (sleeping and awake infants). The analyses were performed with the 32 infants where we had EEG recording. ${ }^{1}$ An alpha level of 0.05 was used, and degrees of freedom were corrected by the conservative Greenhouse-Geisser estimate. All post hoc paired comparisons were performed with the Bonferroni adjustment for multiple comparisons (alpha level of 0.05).

\subsubsection{Neurobehavioral assessment and its association with VEPS}

For the NBAS analysis, the means and standard deviations for the infant's orientation/social interaction and regulation of state clusters were calculated. Then, linear regression analyses, for each VEP component independently, using the enter method, was preformed to verify whether each component could predict sleeping and awake infants' external and internal behavior. The assumptions for performing the regression analysis were met (normal distribu-

\footnotetext{
1 An exploratory analysis conducted with 18 infants who had both VEP and neurobehavioral measures showed similar results.
} 
(a)

Awake

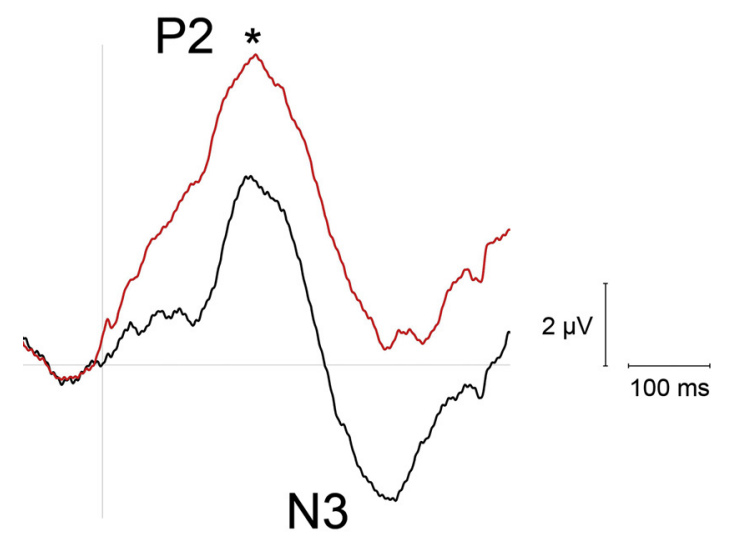

Sleeping

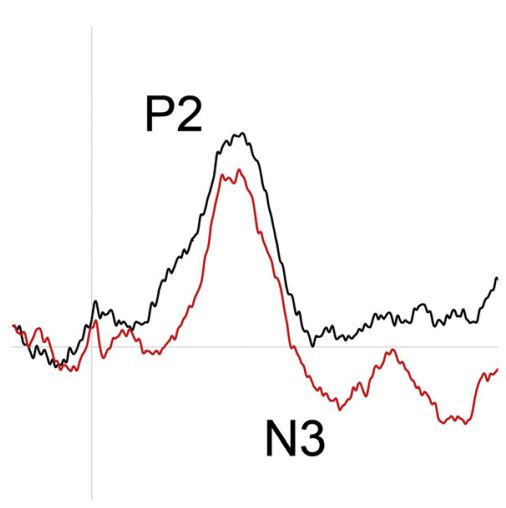

(b)
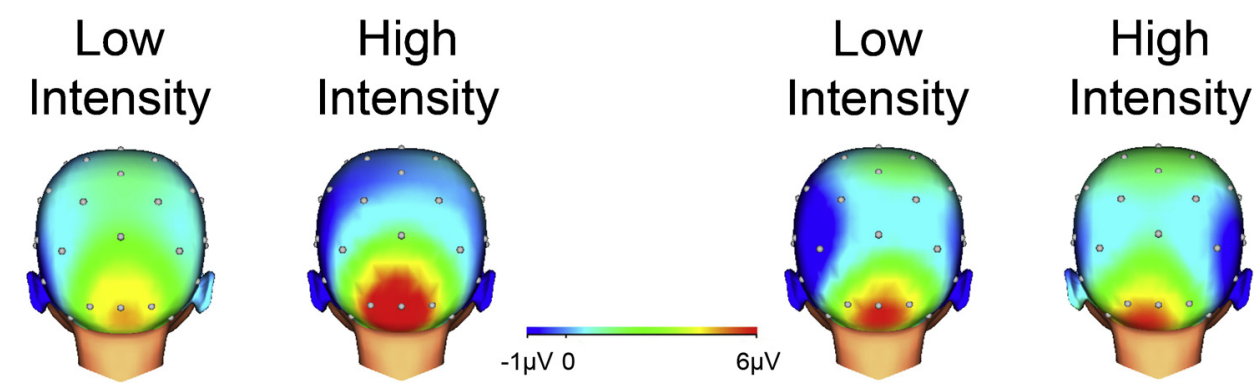

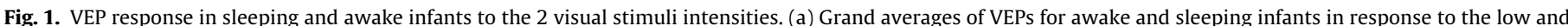

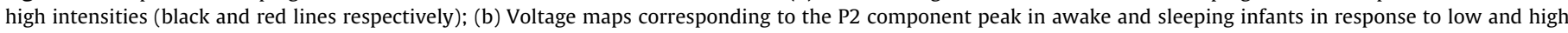
intensities. (For interpretation of the references to color in this figure legend, the reader is referred to the web version of this article.)

tion; no multicollinearity; homoscedasticity; independent errors; independence; standardized residuals). As referred before, 18 participants were included ( 9 infants addressed to the sleep group and the remaining 9 to the awake group) in this analysis. We considered the behavior clusters to be our dependent variable and the VEP intensities stimuli our independent factor/variable.

\section{Results}

Results are reported in two sections: (1) the VEP response to the two visual stimuli intensities in both groups (sleeping and awake infants) and (2) the neurobehavioral profile and its association with the VEPs in the two groups.

\subsection{VEP response in sleeping and awake infants}

The grand averages of the ERPs for the two stimuli intensities (low and high) are shown in Fig. 1 and the amplitude and latency values of $\mathrm{P} 2$ and $\mathrm{N} 3$ components are shown in Table 2.

The analysis of the P2 amplitude revealed a significant interaction between intensity and the infant's state $[\mathrm{F}(130)=4.43, p<.05]$. Post-hoc multiple comparisons (adjusted by Bonferroni correction) indicated that P2 amplitude scores in awake infants were significantly larger in response to the high, comparing with the low intensity $(p=.01)$, whereas no intensity differences were found in the sleeping infants $(p=.80)$.
Regarding the P2 latency, no significant differences were observed in relation to the intensities or interaction with the infant's state.

N3 amplitude and latency was not different between intensities or in its interaction with the infant's state.

\subsection{Association between VEP and neurobehavioral clusters}

All infants displayed organized, coherent and focused behavior, observed in their neurobehavioral profile (see Table 3).

Regarding its association with VEPs, we found that the N3 component amplitude in the lower intensity was correlated with both an adequate external, orienting behavioral performance $\left(R^{2}=0.38\right.$, $p=0.04)$ and an adjusted internal regulation $\left(R^{2}=0.6, p=0.009\right)$ but only in awoken infants. However, no differences were found regarding the $\mathrm{N} 3$ latency for the orienting/social interactive behavior $\left(R^{2}=0.2, p=0.1\right)$ neither for the regulation of state $\left(R^{2}=0.1\right.$,

Table 3

Infants' neurobehavioral profile considering all the NBAS clusters.

\begin{tabular}{ll}
\hline NBAS cluster & Mean (SD) \\
\hline Habituation & $6.6(2.5)$ \\
Orientation & $7.4(1)$ \\
Motor system & $5.7(1.5)$ \\
Range of states & $4(1.7)$ \\
Regulation of states & $5.4(2)$ \\
Autonomic system & $4.4(1.5)$ \\
Reflexes & $1.9(0.3)$ \\
\hline
\end{tabular}


Table 4

Regression analysis results, considering the VEPs components.

\begin{tabular}{|c|c|c|c|c|c|c|c|c|}
\hline & \multicolumn{4}{|l|}{ Social interaction } & \multicolumn{4}{|l|}{ Regulation of state } \\
\hline & $\begin{array}{l}\text { Sleeping - } \\
R^{2} \text { adjusted square }\end{array}$ & $P$ value & $\begin{array}{l}\text { Awake - } \\
R^{2} \text { adjusted square }\end{array}$ & $P$ value & $\begin{array}{l}\text { Sleeping - } \\
R^{2} \text { adjusted square }\end{array}$ & $P$ value & $\begin{array}{l}\text { Awake - } \\
R^{2} \text { adjusted square }\end{array}$ & $P$ value \\
\hline $\begin{array}{l}\text { N2 latency } \\
\text { Intensity } 1\end{array}$ & -0.022 & 0.393 & -0.143 & 0.89 & -0.05 & 0.458 & -0.139 & 0.882 \\
\hline $\begin{array}{l}\text { N2 amplitude } \\
\text { Intensity } 1\end{array}$ & -0.134 & 0.817 & 0.047 & 0.276 & -0.051 & 0.46 & -0.134 & 0.817 \\
\hline $\begin{array}{l}\text { P2 latency } \\
\text { Intensity } 1\end{array}$ & -0.056 & 0.474 & -0.106 & 0.645 & -0.057 & 0.475 & -0.073 & 0.523 \\
\hline $\begin{array}{l}\text { P2 amplitude } \\
\text { Intensity } 1\end{array}$ & -0.093 & 0.589 & -0.113 & 0.68 & -0.06 & 0.484 & -0.119 & 0.713 \\
\hline $\begin{array}{l}\text { N3 latency } \\
\text { Intensity } 1\end{array}$ & -0.093 & 0.589 & 0.202 & 0.125 & -0.015 & 0.378 & 0.105 & 0.206 \\
\hline $\begin{array}{l}\text { N3 amplitude } \\
\text { Intensity } 1\end{array}$ & -0.119 & 0.712 & 0.38 & 0.045 & -0.134 & 0.818 & 0.594 & 0.009 \\
\hline $\begin{array}{l}\text { N2 latency } \\
\text { Intensity } 2\end{array}$ & 0.074 & 0.242 & -0.142 & 0.954 & 0.115 & 0.196 & -0.115 & 0.69 \\
\hline $\begin{array}{l}\text { N2 amplitude } \\
\text { Intensity } 2\end{array}$ & -0.134 & 0.817 & 0.047 & 0.276 & -0.139 & 0.876 & -0.135 & 0.834 \\
\hline $\begin{array}{l}\text { P2 latency } \\
\text { Intensity } 2\end{array}$ & -0.083 & 0.554 & -0.143 & 0.99 & 0.063 & 0.515 & 0.052 & 0.555 \\
\hline $\begin{array}{l}\text { P2 amplitude } \\
\text { Intensity } 2\end{array}$ & -0.119 & 0.709 & -0.109 & 0.658 & -0.135 & 0.829 & -0.133 & 0.811 \\
\hline $\begin{array}{l}\text { N3 latency } \\
\text { Intensity } 2\end{array}$ & -0.114 & 0.681 & -0.141 & 0.925 & -0.143 & 0.97 & -0.08 & 0.543 \\
\hline $\begin{array}{l}\text { N3 amplitude } \\
\text { Intensity } 2\end{array}$ & 0.143 & 0.981 & -0.142 & 0.931 & 0.034 & 0.295 & -0.135 & 0.828 \\
\hline
\end{tabular}

$p=0.2$ ). Similarly, we did not find an association between the higher intensity with orienting/social interactive behavior [N3 amplitude $\left(R^{2}=-0.14, p=0.9\right)$; N3 latency $\left.\left(R^{2}=-0.14, p=0.9\right)\right]$ and regulation of state [N3 amplitude $\left(R^{2}=-0.14, p=0.8\right)$; N3 latency $\left(R^{2}=-0.08\right.$, $p=0.5)$ ] in awake infants. We did not find a statistically significant association regarding the $\mathrm{P} 2$ component (amplitude and latency) in awoken infants and the behavior clusters in the lower and higher intensities (Table 4). Finally, in sleeping infants, we did not find associations between VEPs components (N3 and P2 latency and amplitude) regarding both stimuli intensities (for detailed information see Table 4).

\section{Discussion}

With the present study, our main objectives were: (a) determining which VEP response components were present in 1-month-old infants when presenting them 2 visual unpatterned flash stimuli intensities; (b) verifying if there were differences regarding the visual stimuli processing in the infants who were sleeping and awake during the stimuli presentation; and (c) understanding if the VEP components could predict an adjusted orientation and/or regulation behavior in one-month-old infants.

We found that in both sleeping and awake one-month-old infants, P2 and N3 components were present during the flashlight stimuli, in both lower and higher intensities. Indeed, the presence of these components was a consistent and robust finding observed among all infants. These results are consistent with previous findings (McGlone et al., 2013) suggesting that visual components such as P2 or N3 may reflect a mature brain development in the first weeks of life.

Considering the flash stimuli intensities, our results revealed that the infants displayed greater P2 amplitude in response to the higher intensity stimulus. This was evident only when the infants were awoken. Therefore, these results suggest that the infant's state is crucial for determining different visual processing thresholds. In fact, as it has been reported before (Shepherd et al., 1999), infants' state seem to influence the VEP peaks latency and amplitude regarding the flash visual response, once infants that are awake were reported to display greater amplitudes and shorter peak latencies (Benavente et al., 2005). The present study did not corroborate previous evidence suggesting that there are no differences regarding the VEP characterization in sleeping and awake infants (Barnet et al., 1980; Ellingson, 1970; Ferriss et al., 1967). However, it demonstrated that when studying differences regarding threshold processing, infants' state is essential to the VEP response. This can be due possibly to the fact that similar behavior state may reduce intra and inter-subject variability in very young infants, as suggested by Apkarian et al. (1991). Our study suggests that the infant's neural response to different stimuli may be depending on their behavior state (Prechtl, 1974).

Regarding the neurobehavioral assessment, we hypothesized that one-month-old infants would respond to sensorial stimulation in two behavioral ways: (a) through an external response to the stimuli, and (b) through the infants' ability to regulate themselves in order to respond to that stimulation. These behavioral characteristics are translating social abilities displayed by very young infants (Brazelton and Nugent, 1995). We observed an association between a mature neurobehavioral outcome and the VEP's positive N3 amplitude (once N3 is a negative component higher amplitude means more negativity) in the lower flash intensity. Moreover, once again, these results were only evident in infants that were awoken during the visual stimulation. Indeed, the brain development at young ages is characterized as a complex process that occurs very rapidly, namely a fast increase in synaptic density in the visual cortex in parallel with intense myelination of the visual tracts in the first four postnatal months (Dubois et al., 2008). The infant's physiological response to sensorial stimulation is translated into behavioral characteristics that are associated with spending attentional resources in order to display adequate orienting/social interactive and regulating behavior outcomes (Atkinson, 2002). In fact, infants show different sensorial stimulation input necessities and/or difficulties that are present early in the developmental process (Magnee et al., 2011). For instance, infants who display lower stimuli processing thresholds or seem too disorganized to deal with their context will need different stimuli inputs than those infants who are calmer or require more stimulation to react (Brazelton and Nugent, 1995). Furthermore, it has been suggested that in the first months of life infants present an increase 
sensitivity to lower sensorial information intensities which is consistent with our results regarding the association of N3 in the lower intensity with behavior (Kushnerenko et al., 2013). This way, as suggested by our results, the VEP response to the lower intensity is correlated with an adjusted social interactive and a mature internal regulation profile once the attentional and physiological processes displayed seem to be a demanding process at very young ages. Infants characterized as behaviorally organized are able to regulate themselves to the surrounding stimuli, and consequently, maintaining focused interactive routines. Therefore, an awake state is a requirement for visual processing, as attending and following visual stimuli implies behavioral characteristics only exhibited by awake infants (Atkinson, 2002). Overall, our results seem to suggest that P2 component is associated with visual stimuli threshold discrimination, and N3 component is more likely to be associated with complex interactive abilities. Specifically, P2 has been associated with processing the physical properties of stimuli while N3 with attentional behaviors underlying interactive conditions (Feng et al., 2010; McCulloch and de Haan, 2007).

Nevertheless, we should highlight that the study of VEP in onemonth-old infants is susceptible of great variability. It is clear that additional work is required before a complete understanding of these processes. Thus, further studies contemplating different intensities thresholds in visual processing and its relation to behavioral characteristics should be done with a larger number of participants, as the number of infants in each group is limited. Future studies should also assess infants' physiological characteristics with respect to different sensorial modalities (such as auditory or olfactory processing) and their relationships with neurobehavioral outcome as well as their implications for brain development. Additionally, longitudinal analysis of the VEPs during infancy is required.

\section{Conclusion}

VEP components displayed during visual processing in onemonth-old infants reflect possible brain maturation and are related with mature regulation and interactive abilities at early ages (Isler et al., 2007; Feldman and Eidelman, 2006; Huttenlocher, 2002). Although P2 and N3 components can be identified in sleeping and awoken 1-month-old infants, our results suggest that the infants' state is crucial for the visual processing of different intensities. Furthermore, our results suggest that VEP's N3 component amplitude is associated with mature neurobehavioral outcome in one-month-old infants regarding their interactive and internal regulation behavior. Identifying physiological markers of behavioral outcome can be crucial for an early detection of developmentalrelated problems.

\section{Acknowledgements}

We would like to thank the families and infants who participated in this study. Also, we would like to thank Pedro Hispano Hospital, particularly to Dr. J. Lopes dos Santos, for all the kindness throughout the time that we were there for the data collection process. We thank to Maria de Góis-Eanes for all the help and knowledge entailed throughout this study. Furthermore, we thank Associação Viver a Ciência for the Simbiontes prize in 2013. This work was supported by Fundação Bial (grant number 42/08) and financed by Fundação para a Ciência e Tecnologia (FCT) under a PhD grant (reference SFRH/BD/68263/2010).

\section{References}

Als, H., Tronick, E., Lester, B., Brazelton, T.B., 1977. The Brazelton neonatal behavioral assessment scale (BNBAS). J. Abnorm. Child Psychol. 5 (3), 215-229, http://dx.doi.org/10.1007/BF00913693.

Apkarian, P., Mirmiran, M., Tijssen, R., 1991. Effects of behavioural state on visual processing in neonates. Neuropediatrics $22(2), 85-91$ http://dx.doi.org/10.1055/s-2008-1071422.

Atkinson, J., 2002. The Developing Visual Brain, vol. 32. Oxford University Press, New York, United States.

Barnet, A.B., Friedman, S.L., Weiss, I.P., Ohlrich, E.S., Shanks, B., Lodge, A., 1980. VEP development in infancy and early childhood. A longitudinal study. Electroencephalogr. Clin. Neurophysiol. 49 (5-6), 476-489.

Benavente, I., Tamargo, P., Tajada, N., Yuste, V., Olivan, M.J., 2005. Flash visually evoked potentials in the newborn and their maturation during the first six months of life. Doc. Ophthalmol. 110 (2-3), 255-263, http://dx.doi.org/10.1007/s10633-005-0818-0.

Brazelton, T.B., Nugent, J.K., 1995. Neonatal Behavioral Assessment Scale, vol. 137. 3rd Edition MacKeith Press, London.

Calkins, S.D., Fox, N.A., Marshall, T.R., 1996. Behavioral and physiological antecedents of inhibited and uninhibited behavior. Child Dev. 67 (2), 523-540.

Ceponiene, R., Kushnerenko, E., Fellman, V., Renlund, M., Suominen, K., Naatanen, R., 2002. Event-related potential features indexing central auditory discrimination by newborns. Brain Res. Cogn. Brain Res. 13 (1), 101-113.

Dubois, J., Dehaene-Lambertz, G., Soares, C., Cointepas, Y., Le Bihan, D., Hertz-Pannier, L., 2008. Microstructural correlates of infant functional development: example of the visual pathways. J. Neurosci. 28 (8), 1943-1948, http://dx.doi.org/10.1523/JNEUROSCI.5145-07.2008.

Ellingson, R.J., 1970. Variability of visual evoked responses in the human newborn. Electroencephalogr. Clin. Neurophysiol. 29 (1), 10-19.

Feldman, R., Eidelman, A.I., 2006. Neonatal state organization, neuromaturation, mother-infant interaction, and cognitive development in small-for-gestational-age premature infants. Pediatrics 118 (3), e869-878, http://dx.doi.org/10.1542/peds. 2005-2040.

Ferriss, G.S., Davis, G.D., Dorsen, M.M., Hackett, E.R., 1967. Changes in latency and form of the photically induced average evoked response in human infants. Electroencephalogr. Clin. Neurophysiol. 22 (4), 305-312.

Feng, J.J., Wang, T.X., Yang, C.H., Wang, W.P., Xu, X., 2010. Flash visual evoked potentials at 2-year-old infants with different birth weights. World J. Pediatr. 6 (2), 163-168, http://dx.doi.org/10.1007/s12519-010-0032-3.

Fifer, W.P., Byrd, D.L., Kaku, M., Eigsti, I.M., Isler, J.R., Grose-Fifer, J., Balsam, P.D., 2010. Newborn infants learn during sleep. Proc. Natl. Acad. Sci. U. S. A. 107 (22), 10320-10323, http://dx.doi.org/10.1073/pnas.1005061107.

Huttenlocher, P.R., 2002. The effects of environment on the development of the crebral cortex. In: Neural Plasticity. Harvard University Press, Cambridge, MA.

Huttenlocher, P.R., 2009. Neural Plasticity. Harvard University Press.

Isler, J.R., Grose-Fifer, J., Fifer, W.P., Housman, S., Stark, R.I., Grieve, P.G., 2007. Frequency domain analyses of neonatal flash VEP. Pediatr. Res. 62 (5), 581-585, http://dx.doi.org/10.1203/PDR.0b013e31815586a1.

Jasper, H.H., 1958. The ten twenty electrode system of the international federation. Electroen. Clin. Neuro. 10, 371-375.

Johnson, M.H., Dziurawiec, S., Ellis, H., Morton, J., 1991. Newborns' preferential tracking of face-like stimuli and its subsequent decline. Cognition 40 (1-2), $1-19$.

Jung, T.P., Makeig, S., Westerfield, M., Townsend, J., Courchesne, E., Sejnowski, T.J., 2000. Removal of eye activity artifacts from visual event-related potentials in normal and clinical subjects. Clin. Neurophysiol. 111 (10), 1745-1758.

Kato, T., Watanabe, K., 2006. Visual evoked potential in the newborn: does it have predictive value? Semin. Fetal. Neonatal. Med. 11 (6), 459-463, http://dx.doi.org/10.1016/j.siny.2006.08.003.

Kirk, H.E., Hocking, D.R., Riby, D.M., Cornish, K.M., 2013. Linking social behaviour and anxiety to attention to emotional faces in Williams syndrome. Res. Dev. Disabil. 34 (12), 4608-4616, http://dx.doi.org/10.1016/j.ridd.2013.09.042.

Kraemer, M., Abrahamsson, M., Sjostrom, A., 1999. The neonatal development of the light flash visual evoked potential. Doc. Ophthalmol. 99 (1), 21-39.

Kushnerenko, E., Tomalski, P., Ballieux, H., Ribeiro, H., Potton, A., Axelsson, E.L., Moore, D.G., 2013. Brain responses to audiovisual speech mismatch in infants are associated with individual differences in looking behaviour. Eur. J. Neurosci. 38 (9), 3363-3369, http://dx.doi.org/10.1111/ejn.12317.

Lester, B.M., Als, H., Brazelton, T.B., 1982. Regional obstetric anesthesia and newborn behavior: a reanalysis toward synergistic effects. Child Dev. 53 (3), 687-692.

Liu, J., Bann, C., Lester, B., Tronick, E., Das, A., Lagasse, L., Bada, H., 2010. Neonatal neurobehavior predicts medical and behavioral outcome. Pediatrics 125 (1), e90-98, http://dx.doi.org/10.1542/peds. 2009-0204.

Magnee, M.J., de Gelder, B., van Engeland, H., Kemner, C., 2011. Multisensory integration and attention in autism spectrum disorder: evidence from event-related potentials. PLoS ONE 6 (8), e24196, http://dx.doi.org/10.1371/journal.pone.0024196.

Majnemer, A., Rosenblatt, B., Riley, P.S., 1990. Prognostic significance of multimodality evoked response testing in high-risk newborns. Pediatr. Neurol $6(6), 367-374$.

McGlone, L., Hamilton, R., McCulloch, D.L., Boulton, R., Bradnam, M.S., Weaver, L.T., Mactier, H., 2013. Neonatal visual evoked potentials in infants born to mothers prescribed methadone. Pediatrics 131 (3), e857-863, http://dx.doi.org/10.1542/peds. 2012-2113. 
McCulloch, D.L., de Haan, M., 2007. Visual evoked potentials in infants Infant EEG Event-Related Potentials. 39-63.

Mento, G., Bisiacchi, P.S., 2012. Neurocognitive development in preterm infants: insights from different approaches. Neurosci. Biobehav. Rev. 36 (1), 536-555, http://dx.doi.org/10.1016/j.neubiorev.2011.08.008.

Mercuri, E., von Siebenthal, K., Tutuncuoglu, S., Guzzetta, F., Casaer, P., 1995. The effect of behavioural states on visual evoked responses in preterm and full-term newborns. Neuropediatrics 26 (4), 211-213, http://dx.doi.org/10.1055/s-2007-979756.

Mikkola, K., Kushnerenko, E., Partanen, E., Serenius-Sirve, S., Leipala, J., Huotilainen, M., Fellman, V., 2007. Auditory event-related potentials and cognitive function of preterm children at five years of age. Clin. Neurophysiol. 118 (7), 1494-1502, http://dx.doi.org/10.1016/j.clinph.2007.04.012.

Odom, J.V., Bach, M., Brigell, M., Holder, G., McCulloch, D., Tormene, A., Vaegan, 2010. ISCEV standard for clinical visual evoked potentials (2009 update). Doc. Ophthalmol. 120 (1), 111-119, http://dx.doi.org/10.1007/s10633-009-9195-4.

Pihko, E., Lauronen, L., Wikstrom, H., Taulu, S., Nurminen, J., Kivitie-Kallio, S., Okada, Y., 2004. Somatosensory evoked potentials and magnetic fields elicited by tactile stimulation of the hand during active and quiet sleep in newborns. Clin. Neurophysiol. 115 (2), 448-455.

Prechtl, H.F., 1974. The behavioural states of the newborn infant (a review). Brain Res. 76 (2), 185-212.

Rothbart, M.K., 2007. Temperament, development, and personality. Curr. Dir. Psychol. Sci. 16 (4), 207-212.
Sampaio, A., Sousa, N., Fernandez, M., Henriques, M., Goncalves, O.F., 2008. Memory abilities in Williams syndrome: dissociation or developmental delay hypothesis? Brain Cogn. 66 (3), 290-297. http://dx.doi.org/10.1016/j.bandc.2007.09.005.

Shepherd, A., Saunders, K., McCulloch, D., 1999. Effect of sleep state on the flash visual evoked potential. A case study. Doc. Ophthalmol. 98 (3), 247-256.

Sprangler, G., Fremmer-Bombik, E., Grossmann, K., 1996. Social and individual determinants of infant attachment security and disorganization. Infant Mental Health J. 17 (2), 127-139,

http://dx.doi.org/10.1002/(SICI)1097-0355(199622)17 $: 2<127::$ AID-IMHJ3>3.0.CO;2-N

Stanley, O., Wright, M., Pike, A., Marlow, N., Pike, R., 2009. 'Weight of Evidence' analysis of neonatal sensory evoked potentials. J. Neurosci. Methods 185 (1), 99-107, http://dx.doi.org/10.1016/j.jneumeth.2009.09.020.

Tsuneishi, S., Casaer, P., Fock, J.M., Hirano, S., 1995. Establishment of normal values for flash visual evoked potentials (VEPs) in preterm infants: a longitudinal study with special reference to two components of the N1 wave. Electroencephalogr. Clin. Neurophysiol. 96 (4), 291-299.

Whyte, H.E., Pearce, J.M., Taylor, M.J., 1987. Changes in the VEP in preterm neonates with arousal states, as assessed by EEG monitoring. Electroencephalogr. Clin. Neurophysiol. 68 (3), 223-225. 